\title{
Influência de técnicas de enriquecimento ambiental no aumento do bem-estar de Callithrix penicillata (E. Geoffroy, 1812) (Primates: Callitrichidae)
}

\author{
Mariana Prado Borges* \\ Jonas Byk \\ Kleber Del-Claro \\ Instituto de Biologia, Universidade Federal de Uberlândia \\ Avenida Ceará, $\mathrm{s} / \mathrm{n}^{\circ}$, Campus Umuarama - Bloco 2D, sala 28 \\ CEP 38.400-902, Uberlândia - MG, Brasil \\ *Autor para correspondência \\ mari.prb@gmail.com
}

Submetido em 24/04/2010

Aceito para publicação em 08/10/2010

\section{Resumo}

Este estudo aplicou técnicas de enriquecimento ambiental em um grupo cativo de Callithrix penicillata (saguis-de-tufos-pretos) com o objetivo de aumentar o bem-estar desses animais. O enriquecimento foi realizado com seis animais, três machos e três fêmeas, do Zoológico do Parque Municipal do Sabiá (Uberlândia, MG, Brasil). Os dados foram coletados em três fases, pré-enriquecimento, enriquecimento e pós-enriquecimento, cada uma com $40 \mathrm{~h}$ de observações quantitativas. Foram utilizados dois modelos de enriquecimento sensorial e quatro modelos de enriquecimento alimentar. A resposta comportamental ao enriquecimento foi positiva. Foi observado aumento em alguns comportamentos, como exploratórios, de forrageio, sociais e territoriais, ao passo que outros diminuíram como os estereótipos (indicativos de estresse). Durante e após o enriquecimento houve exibição de comportamentos antes não expressos, principalmente os relacionados à reprodução e socialização. As mudanças comportamentais observadas indicam que o enriquecimento promoveu uma melhora na qualidade de vida dos animais.

Palavras-chave: Callithrix penicillata, Enriquecimento ambiental, Estresse, Primata, Zoológico

\section{Abstract}

Influence of environmental enrichment techniques in improvement of welfare of Callithrix penicillata (E. Geoffroy, 1812) (Primates: Callitrichidae). This study applied environmental enrichment techniques to a captive Callithrix penicillata group aiming to improve the welfare of these animals. Enrichment was carried out with six animals, three males and three females, of Sabiá Municipal Park zoo (Uberlândia, MG, Brazil). Data were collected in three phases, before enrichment, during enrichment and after enrichment, each phase with $40 \mathrm{~h}$ of quantitative observations. We used two sensorial and four feeding enrichment devices. The animals' responses to the enrichment were positive. We observed an increase in some of the behavioral categories, such as "exploring", "foraging", "social" and "territorial". On the other hand, other behaviors decreased, e.g. "stereotypic" (a behavior that indicates stress). During and after the application of enrichment, new behaviors appeared particularly reproductive behaviors, which we had not seen previously. The behavioral changes observed indicate that the enrichment promoted an increase in welfare.

Key words: Callithrix penicillata, Environmental enrichment, Primate, Stress, Zoo 


\section{Introdução}

Bem-estar animal é definido, de forma geral, como a manutenção do animal em boas condições de saúde física e mental, ou seja, é garantir que o animal tenha suas necessidades atendidas, como acesso a alimento e água, conforto, melhorias ambientais e prevenção de doenças infecciosas (YOUNG, 2003). Os mecanismos reguladores que garantem a homeostase em um organismo são influenciados por imposições ambientais. Quando tais imposições são nocivas, intensas ou prolongadas a ponto de alterarem o balanço homeostático, o animal experimenta efeitos adversos, tais como medo, dor, desconforto, ferimento, doenças ou distúrbios comportamentais (BROOM; JONHSON, 1993).

No contexto de animais cativos, o cativeiro impõe aos animais selvagens um ambiente diferente daquele no qual a espécie evoluiu (SGAI, 2007). O cativeiro é tipicamente caracterizado por alta densidade populacional, espaço limitado, baixa pressão predatória, fácil acesso à comida e barreiras físicas prevenindo a dispersão e a imigração (NEWBERRY, 1993). Desta forma, as condições ambientais às quais animais cativos são submetidos podem afetar o bem-estar dos mesmos.

Em se tratando do bem-estar animal, a palavra estresse se refere à falência nas tentativas de enfrentar as dificuldades. Em outras palavras, os sistemas de controle que regulam a homeostasia corporal e as respostas aos perigos não conseguem prevenir uma alteração de estado além dos níveis toleráveis (BROOM; MOLENTO, 2004). Através da avaliação da saúde física e dos padrões comportamentais da espécie é possível avaliar o estresse e o bem-estar psicológico de um animal cativo. Recentes estudos examinaram categorias de parâmetros endócrinos na tentativa de avaliar o bem-estar psicológico, tendo nas variações dos níveis de cortisol um indicador indireto da intensidade da resposta a estímulos estressantes (SGAI, 2007). Já em relação aos padrões comportamentais, alguns aspectos nos permitem medir a baixa qualidade de vida dos animais, como distúrbios comportamentais (e.g. estereótipos, automutilação) e supressão de padrões comportamentais normais (YOUNG, 2003).

Uma das formas de garantir o bem-estar de animais cativos é através do enriquecimento ambiental. O enriquecimento ambiental constitui-se de uma série de métodos e procedimentos que modificam o ambiente físico ou social do cativeiro, após a identificação das necessidades comportamentais dos animais (BOERE, 2001). Na prática, abrange uma variedade de técnicas originais e criativas para manter os animais cativos ocupados através do aumento da gama e diversidade de oportunidades comportamentais e do oferecimento de ambientes mais estimulantes (SHEPHERDSON, 1998). O principal objetivo dos programas de enriquecimento é centrado em dar aos animais mais controle de suas vidas, de forma a possibilitar que eles ocupem o tempo com atividades próprias da espécie (BEKOFF, 1998). Através dele os indivíduos têm a possibilidade de escolha do tipo de ambiente a ser usufruído, possuem maiores possibilidades de exploração e um pouco de controle de sua dieta. Ele também propicia imprevisibilidade ambiental, companheirismo e privacidade (YOUNG, 2003).

Dentre os primatas, o gênero Callithrix apresenta seis espécies de saguis distribuídas no Brasil (RYLANDS et al., 2000). Callithrix penicillata (E. Geoffroy, 1812), popularmente conhecido como sagui-de-tufos-pretos, é um pequeno primata distinguível pelos tufos auriculares pretos em forma de pincel e que ocupa a região central do Brasil (MIRANDA; FARIA, 2001). O corpo desses animais chega a medir $75 \mathrm{~cm}$ de comprimento incluindo a cauda e possui massa que varia de 350 a $400 \mathrm{~g}$ (HERSHKOVITZ, 1977 apud CAVALHEIRO, 2008). Os grupos sociais possuem de 3 a 15 indivíduos, em geral compostos por membros familiares e migrantes não aparentados (DECANINI; MACEDO, 2008). Os saguis, em geral, se alimentam de exudatos vegetais, principalmente goma, frutas, flores, néctar, sementes e pequenos animais, principalmente insetos (MARTINS; SETZ, 2000). Sgai (2007) comprovou que a introdução de técnicas de enriquecimento alimentar e ambiental para saguis cativos aumenta o comportamento exploratório, resultando no aumento de atividade dos animais e diminuindo o comportamento estereotipado.

O presente estudo teve por objetivo aplicar técnicas de enriquecimento ambiental para saguis-de-tufos-pretos cativos, com o intuito de verificar se o enriquecimento promoveria um aumento no bem-estar dos indivíduos mantidos em cativeiro. 


\section{Material e Métodos}

\section{Local e grupo de estudo}

O estudo foi realizado no Zoológico do Parque Municipal do Sabiá, (4814'02”O, 18 $54^{\circ}$ '52”S), em Uberlândia, MG, Brasil. O zoológico possui 51 recintos que abrigam 73 diferentes espécies de mamíferos, aves e répteis. Estas espécies necessitam constantemente de cuidados especiais, como água, alimentos e acompanhamento médico veterinário (RESENDE; SILVA, 2005).

Os dados foram coletados entre os meses de junho de 2007 e outubro de 2008 com o grupo cativo de Callithrix penicillata. No início desse estudo, o grupo era composto por cinco animais adultos não aparentados (três machos e duas fêmeas). Contudo, uma fêmea juvenil foi introduzida no grupo durante a fase de introdução do enriquecimento. Os animais foram distinguidos entre si através da pelagem, tamanho da cauda, tamanho do animal e comportamento. Os animais foram nomeados como Macho I, Macho II, Macho III e Fêmea I, Fêmea II, Fêmea III, sendo esta última a que foi introduzida posteriormente.

\section{Descrição do cativeiro}

O recinto (Figura 1) que abriga os animais apresenta as seguintes dimensões: $4,1 \mathrm{~m}$ de largura $\mathrm{x} 6 \mathrm{~m}$ de comprimento $\mathrm{x} 3,1 \mathrm{~m}$ de altura. As paredes são feitas de tijolos de barro e a parte anterior é fechada por uma tela de $3,8 \mathrm{~m}$ por $3,1 \mathrm{~m}$. O teto é constituído de laje ao fundo do recinto ( $1 / 3$ da área) e tela losangular de malha $2 \times 2 \mathrm{~cm}$ nas partes anterior e mediana. $\mathrm{O}$ solo é coberto por grama e existe uma área acimentada ao fundo da área ( $1 / 3$ do tamanho total do recinto). $O$ cativeiro possui ainda um abrigo de madeira de aproximadamente $0,18 \mathrm{~m}^{2}$ por $0,8 \mathrm{~m}$ de altura que se encontra a $1,8 \mathrm{~m}$ do solo, um recipiente plástico com água, cipós secos e troncos de árvores, uma fonte d'água feita de pedras (desativada) e vegetação diversificada composta por arbustos e várias plantas herbáceas, sendo a maior parte espécies exóticas.

\section{Experimento}

O estudo foi executado em três fases: préenriquecimento, enriquecimento e pós-enriquecimento. Foram realizadas 40 sessões de observações em cada fase do estudo. Cada sessão teve duração de uma hora. As sessões ocorreram no período da manhã em dias sem chuva. Foi feita apenas uma sessão por dia, duas ou três vezes por semana. Os indivíduos foram observados segundo a combinação dos métodos de amostragem instantânea e animal focal (DEL-CLARO, 2004). Cada indivíduo era observado individualmente durante dois minutos e a cada 30seg era registrado um evento comportamental. Decorrido os dois minutos trocava-se o animal observado por outro, realizando um rodízio entre os indivíduos.

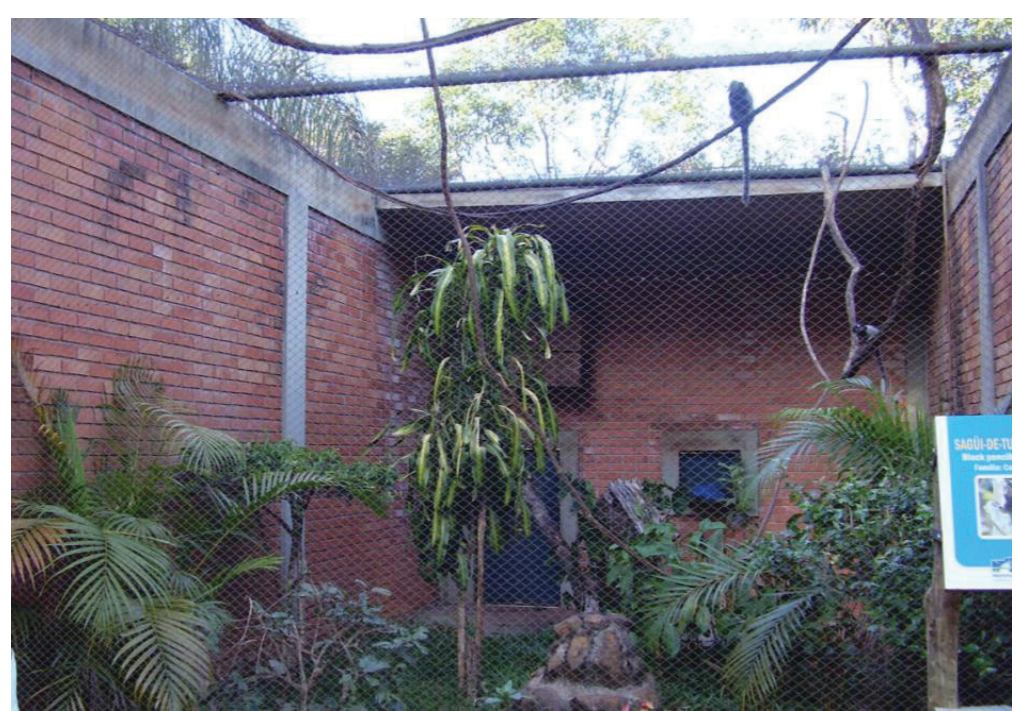

FIGURA 1: Recinto que abriga o grupo de Callithrix penicillata no Zoológico do Parque Municipal do Sabiá, Uberlândia, MG, Brasil. 
A primeira fase consistiu no levantamento dos comportamentos exibidos pelos indivíduos do grupo, avaliando, assim, o grau de bem-estar dos mesmos. Os eventos comportamentais foram descritos e agrupados em categorias definidas pelos pesquisadores de acordo com a natureza dos comportamentos, e.g. comportamentos de natureza exploratória dentro da categoria exploração.

A segunda fase foi a introdução das técnicas de enriquecimento. Essa iniciou com a quebra do condicionamento dos animais. Animais cativos estão submetidos a uma rotina, que faz com que os mesmos fiquem condicionados a receber alimentação e cuidados em horários previstos. Para que os resultados do programa de enriquecimento ambiental não sejam influenciados por esse condicionamento, é necessário que ele seja “quebrado". Para isso, foi necessário alterar o horário de alimentação do grupo, atrasando o mesmo em uma hora. Esse procedimento foi feito duas vezes por semana durante duas semanas. Nos dias em que ocorreu o atraso da alimentação, os animais foram acompanhados durante uma hora após ser colocada a alimentação. Após a quebra do condicionamento, iniciou-se a introdução do enriquecimento em si. Os tipos de enriquecimento utilizados no estudo foram o sensorial e o alimentar.

A proposta do enriquecimento sensorial é fazer com que os animais explorem mais o ambiente, sem a obrigatoriedade de oferecer recursos alimentares. Baseado nesse objetivo, criou-se modelos visuais onde condimentos e ervas que exalam odor foram introduzidos, combinando a utilização de dois sentidos para a exploração dos modelos sensoriais, visão e olfato. Esse enriquecimento sensorial foi escolhido tendo por base os sentidos que os animais utilizam para explorar o ambiente. Os saguis utilizam principalmente a visão e a memória para encontrar recursos alimentares, sem contribuição significativa do olfato (NUNES, 2006). Porém, o olfato é utilizado pelos animais para explorar e avaliar os recursos encontrados, uma vez que saguis utilizam pistas visuais e olfativas para distinguir alimentos palatáveis (LASKA; METZKER, 1998). Os itens olfativos utilizados foram: botão seco de flor de cravo-da-índia (Syzygium aromaticum (L.) Merr. et Perry), folhas secas de canela (Cinnamomum zeylanicum Breyn.), folhas secas de orégano (Origanum vulgare Linn.), folhas de erva-cidreira (Melissa officinalis Linn.), folhas de boldo-de-jardim (Coleus barbatus Benth.), bulbos de alho (Allium sativum Linn.) e cheiro verde (folhas de salsa [Petroselinum crispum (Mill.) Nym.] e cebola [Allium cepa Linn.]). Os itens visuais utilizados foram: bambus (Figura 2-A) e pequenas caixas de papelão (Figura 2-B). Em cada item visual (bambu ou caixa), foram colocadas $25 \mathrm{~g}$ de um dos itens olfativos descritos, envolto em algodão, sendo colocados seis tipos por dia de observação. As combinações dos itens olfativos foram alternadas entre os dias.

Foram utilizados quatro modelos de enriquecimento alimentar. O primeiro consistiu de flores de hibisco
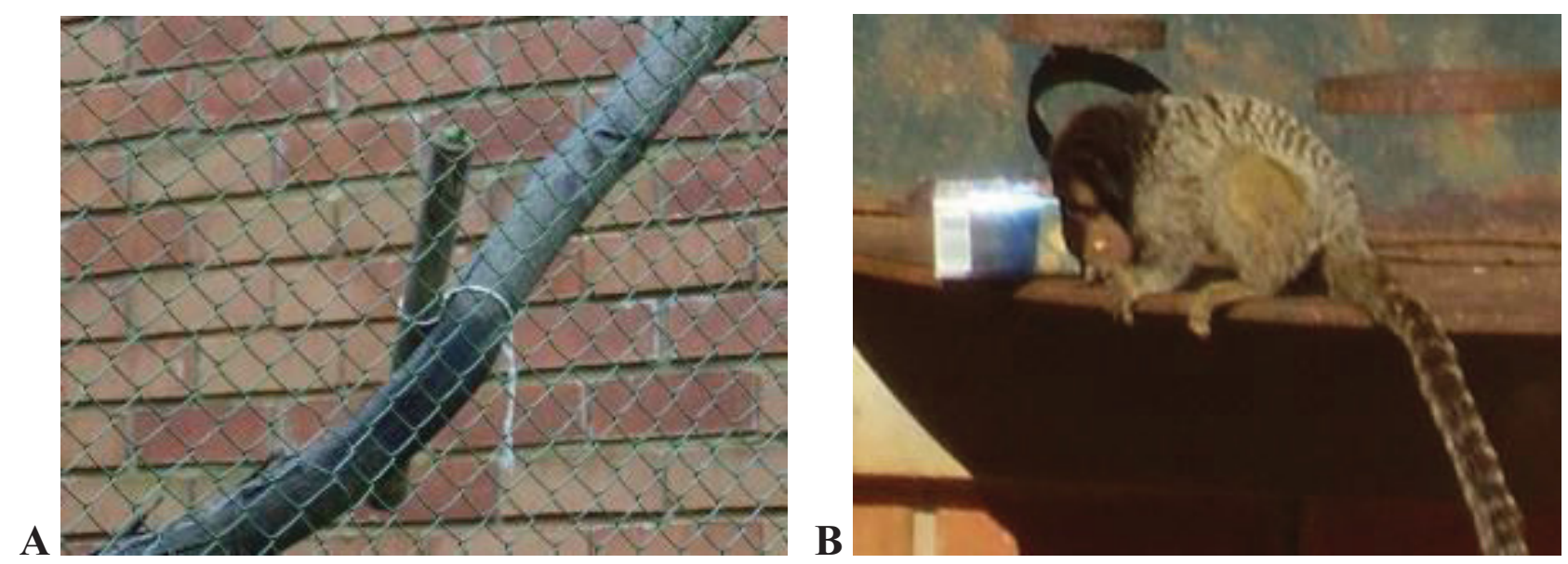

FIGURA 2: Modelos de enriquecimento sensorial. A-Bambu contendo condimentos ou ervas; B - Caixa de papelão contendo condimentos e possuindo pequenos furos nas laterais. 
(Hibiscus rosa-sinensis Linn.) com mel que foram espalhadas pelo recinto (Figura 3-A). O segundo consistiu em ofertar alimento, frutas e carne crua moída, dentro de rodas de madeira perfuradas. Essas rodas possuem $8 \mathrm{~cm}$ de diâmetro e $3 \mathrm{~cm}$ de espessura com três orifícios aonde o alimento foi colocado (Figura 3-B). O terceiro modelo foi similar ao segundo, porém ao invés de utilizar-se de rodas de madeira, foram utilizadas garrafas PET (politereftalato de etileno) transparentes de $600 \mathrm{ml}$ contendo frutas no interior. Essas garrafas foram cortadas ao meio e fechadas com plástico transparente (Figura 3-C). O único orifício de acesso ao alimento pelos animais era um furo de $3 \mathrm{~cm}$ de diâmetro feito na lateral da garrafa. O quarto modelo consistiu na introdução de ninhos artificiais, feitos de casca de coco e palha, com ovos crus de codorna.

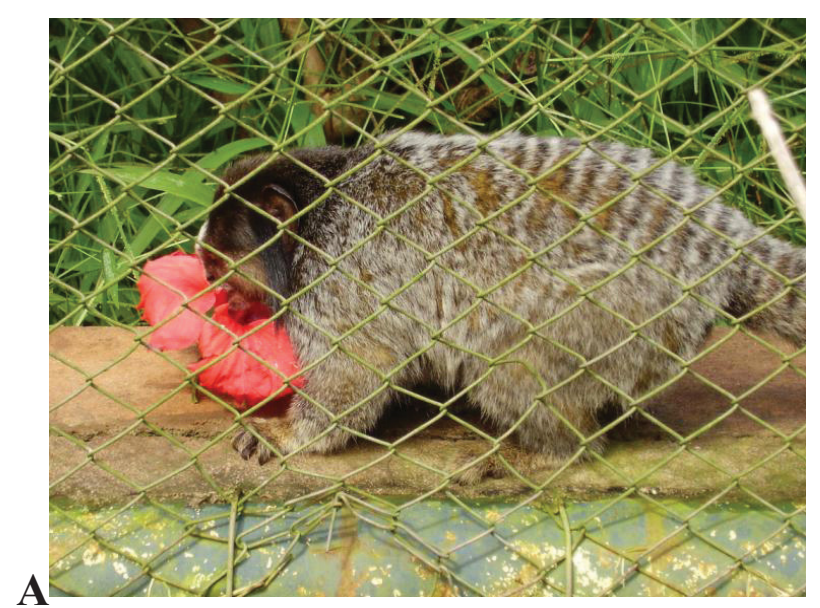

Foi introduzido um tipo de modelo (dos descritos acima) de cada vez, sendo cada modelo introduzido seis vezes. Para evitar confrontos, o número de itens introduzidos respeitava a proporção de um item para cada indivíduo. Os modelos de enriquecimento foram colocados em locais aleatórios dentro do cativeiro. Os objetos eram inseridos no recinto antes das observações e retirados no dia seguinte, sendo que somente eram introduzidos novamente no próximo dia de observação. As observações ocorreram durante o período de uma hora iniciada após a introdução dos modelos.

A última fase foi a de pós-enriquecimento. Essa etapa foi importante para avaliar os efeitos do enriquecimento, comparando os comportamentos exibidos na fase anterior ao mesmo.

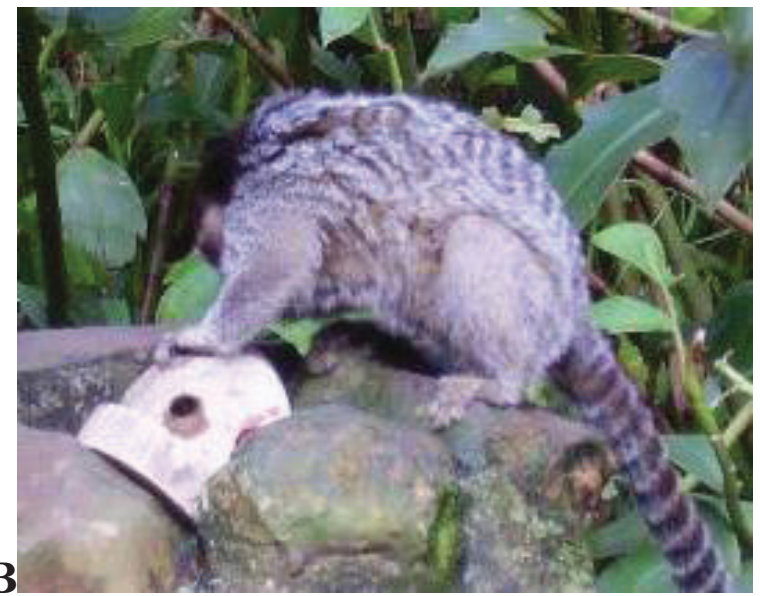

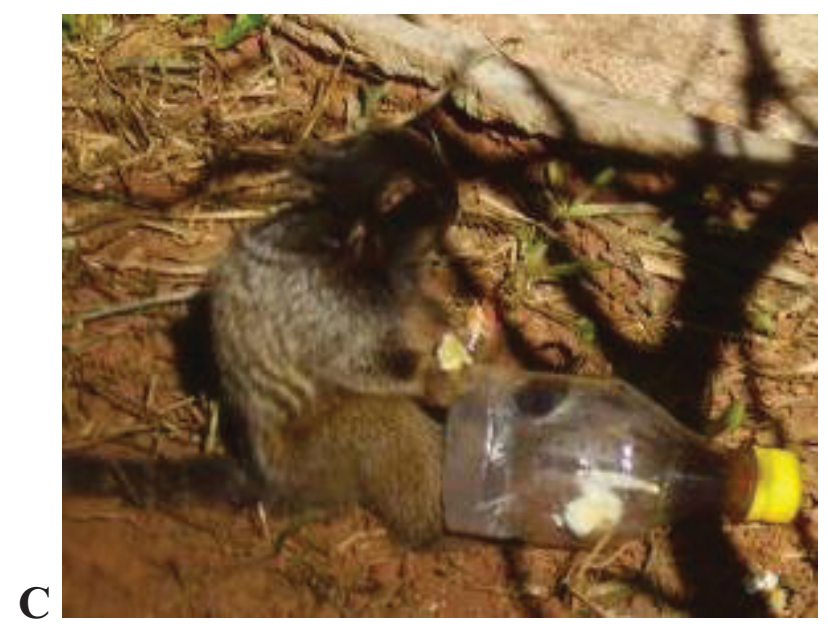

FIGURA 3: Modelos de enriquecimento alimentar: A - Flor de hibisco (Hibiscus rosa-sinensis) com mel; B - Roda de madeira; C - Garrafa PET com única abertura a perfuração lateral. 


\section{Análise dos dados}

Os comportamentos exibidos na fase de pósenriquecimento foram comparados com os exibidos na fase de pré-enriquecimento utilizando o Teste-G para duas amostras independentes, através do programa Bioestat 3.0. Para determinar se houve interação diferenciada dos animais com os distintos modelos de enriquecimento, foi utilizado o teste Kruskal-Wallis, através do programa Systat 10.2. Esse teste foi realizado considerando apenas os indivíduos presentes no início do estudo, uma vez que o animal inserido durante o estudo (Fêmea III) não estava presente na introdução de alguns modelos. Em todos os testes o nível de significância admitido foi $p<0,05$. Foi usada estatística não paramétrica, pois os dados não apresentaram distribuição normal.

\section{Resultados}

Os comportamentos exibidos pelos animais nas fases pré e pós-enriquecimento foram classificados (Tabela 1) e quantificados na (Tabela 2). Na fase de pré-enriquecimento os animais apresentaram 28 atos comportamentais classificados dentro de 13 categorias (Tabela 2). Na fase de pós-enriquecimento foram exibidos 12 novos comportamentos (em negrito na Tabela 2) que não foram apresentados pelos animais na fase de pré-enriquecimento, totalizando 40 atos comportamentais inseridos em 14 categorias, representando um aumento de 39,3\%. Um dos comportamentos exibidos na fase pré-enriquecimento (aquecer-se em grupo utilizando calor corporal), não foi verificado na fase pós-enriquecimento.

TABELA 1: Descrição dos eventos comportamentais exibidos pelo grupo cativo de Callithrix penicillata.

\begin{tabular}{|c|c|}
\hline $\begin{array}{c}\text { Categoria - Evento } \\
\text { comportamental }\end{array}$ & Descrição do evento comportamental \\
\hline Social - Catação em dupla / catado & $\begin{array}{l}\text { Indivíduo é catado por outro indivíduo. Entende-se por catação quando um indi- } \\
\text { víduo inspeciona os pelos, removendo sujeira e ectoparasitos, utilizando as mãos, } \\
\text { língua ou dentes }\end{array}$ \\
\hline Social - Catação em dupla / catando & Indivíduo cata outro indivíduo \\
\hline Social - Catação em grupo & $\begin{array}{l}\text { Indivíduo se encontra em meio a dois ou mais indivíduos em que todos se alter- } \\
\text { nam no ato de catar e serem catados }\end{array}$ \\
\hline $\begin{array}{l}\text { Social - Interação com indivíduo do } \\
\text { recinto ao lado }\end{array}$ & $\begin{array}{l}\text { Indivíduo interage com algum dos indivíduos do recinto ao lado (Callithrix jacchus), } \\
\text { comumente colocando a pata para fora da grade e tocando o indivíduo vizinho }\end{array}$ \\
\hline Social - Brincando de Brigar & $\begin{array}{l}\text { Indivíduo juvenil simula confrontos com intuito não agressivo, típicos de brinca- } \\
\text { deiras de infantes }\end{array}$ \\
\hline Exploração - Andando pelo recinto & $\begin{array}{l}\text { Explorar o ambiente ao seu redor utilizando os sentidos e locomovendo-se no } \\
\text { meio }\end{array}$ \\
\hline Exploração - Olhar na fresta & $\begin{array}{l}\text { Indivíduo permanece olhando através de uma pequena fresta existente no portão } \\
\text { aos fundos do recinto que dá acesso à área de cambeamento }\end{array}$ \\
\hline Exploração - Na grade & $\begin{array}{l}\text { Indivíduo fica parado ou locomovendo-se na grade frontal observando o ambiente } \\
\text { externo ao recinto }\end{array}$ \\
\hline Exploração - Brincadeira exploratória & $\begin{array}{l}\text { Indivíduo observa e manipula algum objeto por longos períodos, mas não o coloca } \\
\text { na boca, nem mastiga ou ingere, mas por vezes o lambe rapidamente. }\end{array}$ \\
\hline $\begin{array}{l}\text { Alimentação exclusiva do cativeiro* } \\
\text { - Comendo alimento colocado }\end{array}$ & Indivíduo se alimenta do alimento oferecido pelo zoológico em vasilhame \\
\hline $\begin{array}{l}\text { Alimentação exclusiva do cativeiro* } \\
\text { - Beber água }\end{array}$ & Indivíduo bebe água oferecida pelo zoológico em vasilhame \\
\hline Forrageio - Forragear & $\begin{array}{l}\text { Indivíduo procura por seu alimento, inspecionando substrato, manipulando e } \\
\text { comendo alimento que encontrou }\end{array}$ \\
\hline Forrageio - Caçar & $\begin{array}{l}\text { Indivíduo caça por insetos ou pequenos vertebrados, exibindo movimentos próprios } \\
\text { de espreita e ataque** }\end{array}$ \\
\hline Forrageio - Comendo o que caçou & Indivíduo se alimenta da presa que caçou \\
\hline $\begin{array}{l}\text { Forrageio - Lambendo restos de } \\
\text { alimento }\end{array}$ & $\begin{array}{l}\text { Indivíduo lambe restos de alimentos nas mãos ou pelos, proveniente de alimento } \\
\text { que caçou ou forrageou }\end{array}$ \\
\hline
\end{tabular}




\begin{tabular}{|c|c|}
\hline Agonístico - Grito agonístico & $\begin{array}{l}\text { Indivíduo emite de sons agressivos e contínuos, diferentes da vocalização de longa } \\
\text { distância (assobio) }\end{array}$ \\
\hline $\begin{array}{l}\text { Agonístico - Perseguição a indivíduo } \\
\text { do grupo }\end{array}$ & Indivíduo persegue outro do cativeiro \\
\hline $\begin{array}{l}\text { Agonístico - Perseguição a indivíduo } \\
\text { de fora }\end{array}$ & $\begin{array}{l}\text { Indivíduo persegue indivíduo livre que se encontra na parte superior do cativeiro, } \\
\text { comumente Callithrix penicillata, seguindo-o pelas telas frontal e superior }\end{array}$ \\
\hline Agonístico - Confronto & $\begin{array}{l}\text { Indivíduo envolvido em confrontos com outro do grupo utilizando gritos e perse- } \\
\text { guição }\end{array}$ \\
\hline Agonístico - Fuga & Indivíduo se desloca ao ser perseguido \\
\hline Coçar - Se coçar & Indivíduo utiliza as mãos para coçar alguma região do corpo \\
\hline Coçar - Coçar-se no cipó & Indivíduo utiliza um cipó (se esfregando) para coçar alguma região do corpo \\
\hline Limpeza - Auto-catação & Indivíduo inspeciona os próprios pelos utilizando as mãos \\
\hline Estereótipos - Pacing & $\begin{array}{l}\text { Indivíduo anda pelo recinto de forma repetitiva e prolongada seguindo uma mesma } \\
\text { trajetória em um circuito }\end{array}$ \\
\hline Estereótipos - Escarificar cipós & $\begin{array}{l}\text { Indivíduo raspa cipós com os dentes sem função aparente, ou seja, fora do contex- } \\
\text { to da marcação ano-genital ou da gomivoria }\end{array}$ \\
\hline Locomoção - Nos galhos, cipós e solo & Indivíduo desloca-se pelo ambiente em galhos e cipós \\
\hline Locomoção - Agitada & Indivíduo desloca-se pelo ambiente de forma rápida e repentina \\
\hline Parado - Descanso & $\begin{array}{l}\text { Indivíduo se mantém parado, embora possa movimentar o corpo, não se desloca } \\
\text { do ponto onde se encontra }\end{array}$ \\
\hline Parado - Vigilância & Indivíduo se mantém parado observando o ambiente a sua volta, estando sob alerta \\
\hline Reclusão - Atrás de arbustos & Indivíduo não esta visível por estar atrás de algum arbusto \\
\hline Reclusão - Dentro do abrigo & Indivíduo dentro do abrigo \\
\hline Aquecimento - Em grupo & Indivíduo busca se aquecer agrupando com outros indivíduos \\
\hline Aquecimento - Ao sol & Indivíduo expõe o corpo ao sol para aque \\
\hline Vocalização - Assobio & $\begin{array}{l}\text { Individuo vocaliza emitindo som longo, agudo e alto, típico de comunicação de } \\
\text { longas distâncias }\end{array}$ \\
\hline Vocalização - Tsik-tsik & $\begin{array}{l}\text { Indivíduo emite sons curtos e baixos, típico de vocalização de alarme a curtas } \\
\text { distâncias }\end{array}$ \\
\hline $\begin{array}{l}\text { Demarcação de território - Mostrar } \\
\text { genitália e/ou urinar }\end{array}$ & Indivíduo urina e/ou mostra genitália para outros indivíduos ou para os observadores \\
\hline $\begin{array}{l}\text { Demarcação de território - Marcação } \\
\text { ano-genital }\end{array}$ & $\begin{array}{l}\text { Indivíduo esfrega região genital em algum substrato após farejá-lo e, em alguns } \\
\text { casos, raspá-lo com os dentes }\end{array}$ \\
\hline Reprodutiva*** - Tentativa de cópula & Indivíduo macho tenta obter cópula com fêmea \\
\hline Reprodutiva*** - Perseguição à fêmea & Indivíduo macho persegue fêmea para obter cópula \\
\hline Reprodutiva*** - Recusa de macho & Indivíduo fêmea recusa tentativa de cópula do macho e foge \\
\hline
\end{tabular}

Notas: *A alimentação exclusiva do cativeiro abrange eventos comportamentais que só podem ser exibidos no ambiente do cativeiro, como comer e beber em vasilhames com recursos. **Optou-se pelo termo "caçar" ao invés de "forrageio de insetos", como é usado na literatura, pois os movimentos exibidos pelos animais assemelham-se ao comportamento de caça. ***Os eventos da categoria reprodutiva só ocorreram entre a Fêmea I e o Macho II.

As análises estatísticas revelaram que quase todas as categorias diferiram significativamente da fase préenriquecimento para pós-enriquecimento. As categorias que apresentaram aumento após o enriquecimento foram: "social" ( $\mathrm{G}=59,38 ; \mathrm{gl}=4 ; \mathrm{p}<0,001)$, "exploração" $(\mathrm{G}$ $=125,73, \mathrm{gl}=3 ; \mathrm{p}<0,001)$, "forrageio" $(\mathrm{G}=59,89$; $\mathrm{gl}=3 ; \mathrm{p}<0,001)$, "agonístico" $(\mathrm{G}=16,33 ; \mathrm{gl}=4 ; \mathrm{p}$ $=0,003)$, "parado" $(\mathrm{G}=123,74 ; \mathrm{gl}=1 ; \mathrm{p}<0,001)$, "reclusão" $(\mathrm{G}=21,62 ; \mathrm{gl}=1 ; \mathrm{p}<0,001)$ e "demarcação de território" $(\mathrm{G}=31,37 ; \mathrm{gl}=1 ; \mathrm{p}<0,001)$. As categorias que diminuíram após o enriquecimento foram: "coçar/ limpeza" $(\mathrm{G}=7,56 ; \mathrm{gl}=2 ; \mathrm{p}=0,023)$, "estereótipos" $(G=12,64 ; g 1=1 ; p<0,001)$, "locomoção" $(G=44,31$; $\mathrm{gl}=1 ; \mathrm{p}<0,001)$ e "aquecimento" $(\mathrm{G}=34,26 ; \mathrm{gl}=1$; $\mathrm{p}<0,001)$. As categorias que não diferiram entre as duas fases foram "vocalização" $(\mathrm{G}=0,05 ; \mathrm{gl}=1 ; \mathrm{p}$ $=0,818)$ e "alimentação exclusiva do cativeiro" $(\mathrm{G}=$ $0,98 ; \mathrm{gl}=1 ; \mathrm{p}<0,321)$. Os comportamentos relacionados à reprodução surgiram apenas após o enriquecimento. 
TABELA 2: Número de eventos comportamentais exibidos antes e depois da aplicação de enriquecimento ambiental para o grupo cativo de Callithrix penicillata.

\begin{tabular}{|c|c|c|c|}
\hline Categorias & Evento & Antes & Depois \\
\hline \multirow{5}{*}{ Social } & Catação em dupla / catado & 36 & 83 \\
\hline & Catação em dupla / catando & 30 & 78 \\
\hline & Catação em grupo & 28 & 6 \\
\hline & Interação com indivíduo do recinto ao lado & $\mathbf{0}$ & 7 \\
\hline & Brincando de brigar & $\mathbf{0}$ & 21 \\
\hline \multirow{4}{*}{ Exploração } & Andar pelo recinto & 424 & 953 \\
\hline & Olhar na fresta & 92 & 59 \\
\hline & Na grade & 277 & 300 \\
\hline & Brincadeira exploratória & $\mathbf{0}$ & 41 \\
\hline \multirow{2}{*}{ Alimentação exclusiva do cativeiro } & Comer alimento colocado & 275 & 354 \\
\hline & Beber água & 10 & 8 \\
\hline \multirow{4}{*}{ Forrageio } & Forragear & 21 & 52 \\
\hline & Caçar (forragear por insetos) & 14 & 81 \\
\hline & Comer o que caçou & $\mathbf{0}$ & 21 \\
\hline & Lamber restos de alimentos & 26 & 7 \\
\hline \multirow{5}{*}{ Agonístico } & Grito agonístico & 11 & 8 \\
\hline & Perseguição a indivíduo do grupo & 3 & 1 \\
\hline & Perseguição a indivíduo de fora & $\mathbf{0}$ & 5 \\
\hline & Confronto & 5 & 22 \\
\hline & Fuga & $\mathbf{0}$ & 2 \\
\hline \multirow{3}{*}{ Coçar/limpeza } & Se coçar & 210 & 153 \\
\hline & Coçar-se no cipó & 21 & 8 \\
\hline & Auto-catação & 52 & 59 \\
\hline \multirow{2}{*}{ Estereótipos } & Pacing & 112 & 28 \\
\hline & Escarificar cipós & 112 & 69 \\
\hline \multirow{2}{*}{ Locomoção } & Nos galhos, cipós e solo & 719 & 552 \\
\hline & Agitada & $\mathbf{0}$ & 27 \\
\hline \multirow{2}{*}{ Parado } & Descanso & 996 & 1115 \\
\hline & Vigilância & 116 & 423 \\
\hline \multirow{2}{*}{ Reclusão } & Atrás de arbustos & 15 & 14 \\
\hline & Dentro do abrigo & 0 & 22 \\
\hline \multirow{2}{*}{ Aquecimento } & Em grupo & 88 & 0 \\
\hline & Ao sol & 159 & 43 \\
\hline \multirow{2}{*}{ Vocalização } & Assobio & 156 & 100 \\
\hline & Tsik-tsik & 29 & 20 \\
\hline \multirow{2}{*}{ Demarcação de território } & Mostrar genitália e/ou urinar & 15 & 8 \\
\hline & Marcação ano-genital & $\mathbf{0}$ & 27 \\
\hline \multirow{3}{*}{ Reprodutiva } & Tentativa de cópula & $\mathbf{0}$ & 8 \\
\hline & Perseguição à fêmea & $\mathbf{0}$ & 10 \\
\hline & Recusa de macho & $\mathbf{0}$ & 5 \\
\hline
\end{tabular}

Nota: Em negrito destacam-se os comportamentos surgidos após o enriquecimento.

A proporção do número de interações com cada modelo de enriquecimento pode ser visualizada na Figura 4. A interação dos animais apresentou diferença entre os modelos (Estatística de Kruskal-Wallis $=11,510 ; \mathrm{p}=$ $0,042 ; \mathrm{df}=5)$. Dos modelos testados, a ordem decrescente de interação foi: rodas de madeira com alimento (Soma dos Ranques $-\mathrm{SR}=654,0$ ); garrafas plásticas com frutas $(\mathrm{SR}=590,0)$; bambus com ervas e condimentos ( $\mathrm{SR}=$ $540,0)$; flores com mel $(\mathrm{SR}=500,5)$; ninho com ovos $(\mathrm{SR}=497,5)$; e caixa com condimentos $(\mathrm{SR}=299,0)$. A 
análise dos modelos par a par identificou que a caixa com condimentos foi significativamente diferente dos outros modelos. Os demais modelos não apresentaram diferenças significativas uns com os outros (Tabela 3).

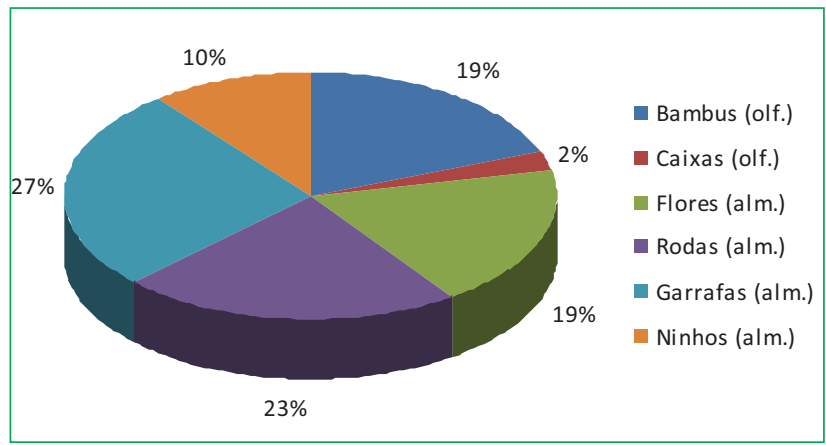

FIGURA 4: Proporção de número de interações dos saguis-detufos-pretos com cada modelo de enriquecimento ambiental.

TABELA 3: Valor de $p$ no teste estatístico de KruskalWallis para a análise de cada par de modelos. Foi considerada significativa as diferença onde $p<0,05$.

\begin{tabular}{lccccc} 
& $\begin{array}{c}\text { Bambus } \\
\text { (olf.) }\end{array}$ & $\begin{array}{c}\text { Caixas } \\
\text { (olf.) }\end{array}$ & $\begin{array}{c}\text { Flores } \\
\text { (alm.) }\end{array}$ & $\begin{array}{c}\text { Rodas } \\
\text { (alm.) }\end{array}$ & $\begin{array}{c}\text { Garrafas } \\
\text { (alm.) }\end{array}$ \\
\hline $\begin{array}{l}\text { Bambus (olf.) } \\
\text { Caixas (olf.) }\end{array}$ & - & & & & \\
$\begin{array}{l}\text { Flores (alm.) } \\
\text { Rodas (alm.) }\end{array}$ & 0,753 & - & & & \\
$\begin{array}{l}\text { Garrafas } \\
\text { (alm.) }\end{array}$ & 0,301 & 0,001 & - & & \\
$\begin{array}{l}\text { Ninhos } \\
\text { (alm.) }\end{array}$ & 0,446 & 0,007 & 0,481 & 0,552 & - \\
\hline
\end{tabular}

\section{Discussão}

As técnicas de enriquecimento ambiental aplicadas no presente estudo mostraram-se eficazes em diminuir os comportamentos estereotipados e aumentar o repertório comportamental de $C$. penicillata em cativeiro. $\mathrm{O}$ aumento da variedade de comportamentos resultou em uma maior exploração do ambiente do cativeiro e diminuição do número de comportamentos estereotipados.

O aumento da diversidade comportamental, em quase $40 \%$, é uma evidência de que o enriquecimento ambiental aumentou o bem-estar dos animais (SHEPHERDSON,
1998; YOUNG, 2003). Outra evidência nesse sentido é o aumento da expressão de comportamentos típicos da espécie. Dentre os comportamentos típicos descritos para saguis-detufos-pretos livres, encontramos a execução da marcação ano-genital (LAZARO-PEREA et al., 1999; CANALE et al., 2008), a exibição de comportamentos ligados a reprodução (DECANINI; MACEDO 2008), além de uma alta frequência de exibição de comportamentos de forrageio, aproximadamente $45 \%$ do tempo (VILELA; FARIA, 2004). Animais com baixa qualidade de vida comumente apresentam supressão de alguns comportamentos típicos (CARLSTEAD; SHEPHERDSON, 1994; YOUNG, 2003). A exibição dos atos comportamentais reprodutivos, da marcação ano-genital e do aumento da frequência de exibição do forrageio (de 1,5\% para 3,5\%) após a introdução do enriquecimento ambiental indicam uma tendência de aproximação do repertório comportamental de indivíduos de vida livre.

O comportamento de marcação ano-genital possui função principal de reconhecimento entre indivíduos do grupo e delimitação da área de vida, é exibido preferencialmente pelas fêmeas como sinal de hierarquia social e é executado comumente em associação com a gomivoria (LAZARO-PEREA et al., 1999; CANALE et al., 2008). A introdução de uma nova fêmea no grupo pode ter influenciado a exibição desse comportamento. No entanto, como sua exibição iniciou ainda durante a fase de enriquecimento antes da introdução da nova fêmea, seu surgimento no grupo está mais relacionado ao enriquecimento do que à chegada da fêmea.

O fato dos comportamentos reprodutivos envolverem apenas dois indivíduos, um macho e uma fêmea, reflete a manifestação de estrutura hierárquica no grupo (DECANINI; MACEDO, 2008). A rejeição da fêmea às investidas do macho deve ser mais bem investigada, pode ser uma supressão de estímulos sexuais devido ao estresse ou uma falta de aprendizado sexual (ZIMMERMANN; NETO, 2007), uma vez que esta fêmea vivia, antes de vir para o zoológico, livre e solitária em ambiente urbano.

Além da maior expressão dos comportamentos de forrageio, houve também aumento dos comportamentos de caráter social e exploratório após o enriquecimento. Sgai et al. (2007), após a introdução de bolas de ping- 
pong com alimento no interior para $C$. penicillata, observaram um aumento nos comportamentos de forrageio, exploração e interações sociais entre os indivíduos. $\mathrm{O}$ aumento da expressão dos comportamentos dessas categorias é forte evidência de aumento do bemestar dos animais (YOUNG, 2003).

A maior expressão dos comportamentos sociais e a exibição de dois novos atos comportamentais indicam que o enriquecimento teve um efeito positivo não somente a nível individual, mas para o grupo como um todo. Segundo Boere (2001), a vida em grupo permite a catação entre os indivíduos, um difundido comportamento entre os primatas que alivia a tensão. A maior expressão de interações sociais revela maior coerção entre os indivíduos, sendo um indício favorável de bem-estar (BROOM; JOHNSON, 1993).

O comportamento específico de "brincar de brigar" pode ter, porém, outra causa que não especificamente o aumento do bem-estar do grupo. Esse comportamento foi exibido principalmente pela Fêmea III e quando exibido pelos demais indivíduos era sempre em resposta ao comportamento iniciado por ela. Essa fêmea é um juvenil, o que justifica a exibição desse tipo de comportamento. Brincar de lutar entre infantes seria uma forma de ensaiar para situações, durante a vida adulta, que envolvam a disputa como forma crítica de sobrevivência (THOMPSON, 1998). Outro comportamento que surgiu nos resultados e que pode ser atribuído ao mesmo motivo é "brincadeira exploratória". Esse comportamento foi exibido exclusivamente pela fêmea III em que ela se locomovia e manipulava os objetos como forma de brincadeira. Em cativeiro, a alta incidência de comportamentos de brincadeiras em jovens primatas é indício de bem-estar (BOERE, 2001).

Já o aumento dos comportamentos exploratórios foi exibido por todos os indivíduos, representando assim uma resposta comportamental positiva do grupo todo ao enriquecimento ambiental. Resultados semelhantes foram encontrados por Lutz e Novak (1995). Estes autores verificaram um aumento na utilização do espaço do cativeiro por indivíduos de macaco-rhesus (Macaca mulatta Zimmermann, 1780) após aplicarem técnicas de enriquecimento ambiental.

Os comportamentos de forrageio e caça tiveram um aumento expressivo, não somente na fase pós- enriquecimento, mas também durante o próprio enriquecimento. A introdução dos modelos alimentares ocorreu várias vezes concomitantemente com a oferta da alimentação pelo zoológico. Em todas as vezes que isso ocorreu, a maioria dos animais preferiu os modelos aos alimentos no vasilhame. Ademais, logo após explorarem os modelos (retirando alimentos, lambendoos, manipulando-os, etc.) a expressão de forrageio e caça aumentava. Young (2003) cita que se o animal prefere o alimento escondido ou de acesso mais dificultado do que o alimento ofertado na vasilha é um sinal de alto bem-estar.

Os comportamentos agonísticos que foram manifestos posteriormente ao enriquecimento não indicam necessariamente que os animais tornaram-se mais agressivos, consequência essa que indicaria que o enriquecimento causou efeitos negativos. Essa afirmação é sustentada em dois pontos: os demais comportamentos analisados aqui indicaram que o enriquecimento surtiu efeitos positivos no bem-estar dos indivíduos; e mesmo tendo aumentado, o grau de agressividade não era alto e nem causavam danos aos indivíduos (e.g. injúrias). Com isso, esse aumento pode ser visto como comportamentos típicos que garantem a hierarquia (DECANINI; MACEDO, 2008) e que estavam suprimidos ou que sofreram alteração devido à introdução da Fêmea III no grupo. Tendo em vista que comportamentos agonísticos intra-grupo são mais comuns durante o período de estabelecimento dos grupos (DIGBY, 1995), a chegada de um novo indivíduo pode aumentar a frequência desses comportamentos.

O marco mais evidente do aumento do bem-estar propiciada pelo enriquecimento foi a diminuição dos comportamentos estereotipados. Aqui foi tomado como estereótipos o pacing e a escarificação de cipós. Saguis costumam escarificar troncos com a finalidade de extrair exudatos vegetais (goma) como recurso alimentar e ao realizar marcação ano-genital (LAZARO-PEREA et al., 1999; MARTINS; SETZ, 2000; CANALE et al., 2008). Canale et al. (2008) descrevem que no contexto de marcação ano-genital a gomivoria e as escarificações a precedem na maioria dos casos. No entanto, os saguis do estudo escarificavam cipós secos, sem exudatos, e exibiam tal comportamento fora do contexto da marcação ano-genital. Por esse motivo, esse comportamento foi considerado como estereótipo. 
Outra evidência de que esse comportamento seria mesmo um estereótipo esta na sua diminuição após o enriquecimento. Se fosse um comportamento com finalidade específica para a espécie, não haveria razão de ele ter diminuído e sua tendência seria aumentar. A diminuição de comportamentos estereotipados é uma evidência comportamental contundente da diminuição do estresse (SHEPHERDSON, 1998; YOUNG, 2003).

Além da diminuição da locomoção na forma de pacing houve diminuição também na locomoção "nos galhos, cipós e solo". Em contrapartida, houve aumento dos comportamentos da categoria "parado" ("descanso" e "vigilância"). O maior tempo sob vigilância demonstra que os indivíduos estão mais atentos ao que ocorre no ambiente. Tal comportamento é descrito na literatura como vigilância anti-predador e faz parte do repertório comportamental natural de callitrichideos, sendo exibidos mesmo por animais nascido em cativeiro (BARROS et. al., 2008; NUNES et al., 2010). Em vida livre, saguis-de-tufos-pretos gastam mais tempo se deslocando, de 22 a 25\% do tempo, do que descansando, de 18 a 20\% do tempo (VILELA; FARIA, 2004). No cativeiro, a exibição de locomoção diminuiu de 15 para $11 \%$ dos atos comportamentais e o descanso aumentou de 20 para 23\%. Essa diferença pode ser explicada pelo fato de que no cativeiro o espaço físico limitado não impõe aos indivíduos a necessidade de realizarem longos deslocamentos. Desta forma, justifica os animais cativos gastarem mais tempo descansando ou sob vigilância do que se locomovendo.

Às vezes em que os animais não estavam visíveis por estarem atrás de plantas ou demais substratos praticamente não alterou de uma fase para a outra. Contudo, quando os animais não estavam visíveis por estarem dentro do abrigo foi manifesto apenas no pósenriquecimento. Nesse caso, permanecer ou entrar no abrigo indica que os animais estão utilizando mais o espaço do cativeiro. Uma das metas de programas de enriquecimento visa fazer com que os animais utilizem mais o espaço (CARLSTEAD; SHEPHERDSON, 1994).

A diminuição nos comportamentos de aquecimento e coçar pode ser atribuída a outros fatores que não ao enriquecimento. No caso do aquecimento está relacionado a diferenças nas temperaturas entre as fases de coleta, já que os dados do pré-enriquecimento foram coletados no inverno e do pós-enriquecimento na primavera. Já o comportamento de coçar pode estar relacionado à quantidade de ectoparasitos (PINHA, 2007) e não há na literatura indícios de que sua expressão esteja ligada diretamente a reflexos de estresse dos indivíduos.

De modo geral, os modelos alimentares foram mais explorados pelos animais do que os sensoriais. Além disso, a interação com os modelos alimentares foi mais diversificada e ocorria de forma mais prolongada em relação aos sensoriais. Essa maior exploração dos modelos alimentares era esperada, uma vez que esses modelos ofereciam recursos aos animais. Isso implica que os indivíduos gastaram algum tempo explorando tais modelos para conseguir acessar os recursos neles contidos. O objetivo principal dos modelos alimentares é adicionar dificuldade ao acesso do alimento. Esse acesso dificultado é uma forma de aproximar os animais cativos às condições existentes em ambientes naturais. Em cativeiro, a comida deveria ser ofertada com a forma e a frequência semelhante ao encontrado em vida livre (JORDAN, 2005). Em relação aos modelos sensoriais sua função é estimular os animais a explorarem mais o ambiente do cativeiro. Apesar da baixa interação com esses modelos, os resultados indicam que eles podem ter contribuído significativamente para o aumento dos comportamentos exploratórios dos animais cativos.

Os resultados do estudo indicam aumento no bem-estar dos animais após a introdução dos modelos de enriquecimento ambiental e mostram a importância da implementação dessas e outras técnicas na rotina dos animais. Porém, para que esses resultados sejam revertidos em melhorias efetivas na qualidade de vida dos animais, a utilização de técnicas de enriquecimento ambiental deve ser realizada de forma contínua e com constante avaliação.

\section{Agradecimentos}

Os autores agradecem à equipe administrativa e funcionários do Zoológico do Parque Municipal do Sabiá pelo apoio e cooperação durante a execução do trabalho; à Profa. Dra. Ana Elizabeth Custódio e à MSc. Vanessa Stefani Moreira pelas contribuições dadas ao artigo. 


\section{Referências}

BEKOFF, M. Making lives richer and better. BioScience, Washington, v. 48, n. 10, p. 854-855, 1998.

BARROS, M.; ALENCAR, C.; SILVA, M. A. D.; TOMAZ, C. Changes in experimental conditions alter anti-predator vigilance and sequence predictability in captive marmosets. Behavioural Processes, Amsterdam, v. 77, n. 3, p. 351-356, 2008.

BOERE, V. Environmental enrichment for neotropical primates in captivity. Ciência Rural, Santa Maria, v. 31, n. 3, p. 543-541, 2001. BROOM, D. M.; JOHNSON, K. G. Stress and strain, welfare and suffering. In: BROOM, D. M.; JOHNSON, K. G. (Ed.). Stress and animal welfare. London: Chapman \& Hall, 1993, p.57-86.

BROOM, D. M.; MOLENTO, C. F. M. Bem-estar animal: conceitos e questões relacionadas - Revisão. Veterinary Science, Seoul, v. 9, n. 2, p. 1-11, 2004.

CANALE, G.; BRAGA, A.; GONDIM, L.; SANTEE, D. Sequência de comportamentos de Callithrix penicillata durante a gomivoria. In: FERRARI, S. F.; RÍMOLI, J. (Ed.). A Primatologia no Brasil -9. Aracaju: Sociedade Brasileira de Primatologia, 2008, p. 49-59. CARLSTEAD, K.; SHEPHERDSON, D. The effects of environmental enrichment on reproduction. Zoo Biology, New York, v. 13, n. 5, p. 447-458, 1994.

CAVALHEIRO, M. C. O brincar em saguis Callithrix penicillata (Primates: Callitrichidae) sob o foco da teoria do excedente de energia. 2008. 86 f. Dissertação (Mestrado em Biologia Animal) Universidade de Brasília, Brasília. 2008.

DECANINI, D. P.; MACEDO, R. H. Sociality in Callithrix penicillata: I. Intragroup male profile. International Journal of Primatology, New York, v. 29, p. 433-447, 2008.

DEL-CLARO, K. Definindo a metodologia. In: DEL-CLARO, K. (Ed.). Comportamento Animal - Uma introdução à ecologia comportamental. Jundiaí: Editora - Livraria Conceito, 2004. p. 5684.

DIGBY, L. J. Social organization in a wild population of Callithrix jacchus: II intragrup social behavior. Primates, Kyoto, v. 36, n. 3, p. 361-375, 1995.

JORDAN, B. Science-based assessment of animal welfare: wild and captive animals. Revue Scientifique et Technique Office International des Épizooties, Paris, v. 24, n. 2, p. 515-528, 2005.

LASKA, M.; METZKER, K. Food avoidance learning in squirrel monkeys and common marmosets. Learning \& Memory, v. 5, p. 193-203, 1998.

LAZARO-PEREA, C.; SNOWDON, C. T.; ARRUDA, M. F. Scentmarking behavior in wild groups of common marmosets (Callithrix jacchus). Behavioral Ecology and Sociobiology, Göttingen, v. 46, p. 313-324, 1999.

LUTZ, C. K.; NOVAK, M. A. Use of foraging racks and shavings as enrichment tools for groups of rhesus monkey (Macaca mulatta). Zoo Biology, New York, v. 14, n. 5, p. 463-474, 1995.

MARTINS, M. M.; SETZ, E. Z. F. Diet of buffy tufted-eared marmosets (Callithrix aurita) in a forest fragment in southeastern Brazil. International Journal of Primatology, New York, v. 21, n. 3, p. 467-476, 2000.

MIRANDA, G. H. B.; FARIA, D. S. Ecological aspects of blackpincelled mamorset (Callithrix penicillata) in the cerradão and dense cerrado of Brazilian Central Plateau. Brazilian Journal of Biology, São Carlos, v. 61, n. 3, p. 397-904, 2001.

NEWBERRY, R. C. The space-time continuum and its relevance to farm animals. Etologia, v. 3, p. 219-234, 1993.

NUNES, A. M. Ecologia cognitiva e forrageio social em híbridos de Callithrix penicillata x Callithrix jacchus (Primates: Cebidae: Callitrichinae) introduzidos na Ilha de Santa Catarina. 2006. 55 f. Dissertação (Mestrado em Zoologia) - Pontifícia Universidade Católica do Rio Grande do Sul, Porto Alegre. 2006.

NUNES, D. M.; GONÇALVES-JUNIOR, I.; EMILE, N.; BARROS, M. Bimodal temporal organization of specific vigilance behaviors in captive black tufted-ear marmosets (Callithrix penicillata). Behavioural Processes, Amsterdam, v. 84, n. 2, p. 629-631, 2010. PINHA, P. S. Interações sociais em grupos de macacos-prego (Cebus libidinosus) no Parque Nacional de Brasília. 2007. 67 f. Dissertação (Mestrado em Ecologia) - Universidade de Brasília, Brasília. 2007.

RESENDE, F. F. B.; SILVA, N. R. Aspectos físico-químicos e indicadores de contaminação microbiológica da água utilizada pelos animais no zoológico do Parque Sabiá-Uberlândia-MGBrasil. Horizonte Científico, Uberlândia, v. 5, v. 2, p. 1-15, 2005.

RYLANDS, A. B.; SCHNEIDER, H.; LANGGUTH, A.; MITTERMEIER, R. A.; GROVES, C. P.; RODRIGUEZ-LUNA, E. An assessment of the biodiversity of New World primates. Neotropical Primates, Arligton, v. 8, n. 2, p. 61-93, 2000.

SGAI, M. G. F. G. Avaliação da influência das técnicas de enriquecimento ambiental nos parâmetros endócrinos e comportamentais de Callithrix penicillata (sagui-de-tufospretos) mantidos em estabilidade social e isolados. $2007.113 \mathrm{f}$. Dissertação (Mestrado em Reprodução Animal) - Universidade de São Paulo, São Paulo. 2007.

SGAI, M. G. F. G.; STASIENIUK, E. V. Z.; ROCHA, C. G.; PORTElA, T. P.; PIZZUTTO, C. S.; GUIMARÃES, M. A. B. V. Ping-pong balls: an economical idea to enrich mamorsets. The Shape of Enrichment, v. 16, n. 1/2, p. 4, 2007.

SHEPHERDSON, D. J. Tracing the path of environmental enrichment in zoos. In: SHEPHERDSON, D. J.; MELLEN, J. D.; HUTCHINS, M. (Ed.). Second nature: environmental enrichment for captive animals. Washington: Smithsonian Institution Press, 1998. p.1-12.

VILELA, S. L.; FARIA, D. S. Seasonality of the activity pattern of Callithrix penicillata (Primates, Callitrichidae) in the cerrado (scrub savanna vegetation). Brazilian Journal of Biology, São Carlos, v. 61, p. 363-370, 2004.

THOMPSON, K. V. Self assessment en juvenile play. In: BEKOFF, M.; BYERS, J. A. (Ed.). Animal play: evolutionary, comparative and ecological perspectives. Cambridge: Cambridge University Press, 1998. p. 183-204.

YOUNG, R. J. Environmental enrichment for captive animals. Oxford: Blackwell Science, 2003. 228 p.

ZIMMERMANN, R. S.; NETO, F. L. Manejo e reprodução de calitriquídeos no criadouro conservacionista da Univap, campus Urbanova. In: ENCONTRO LATINO AMERICANO DE INICIAÇÃO CIENTÍFICA, X, e ENCONTRO LATINO AMERICANO DE PÓS-GRADUAÇÃO, VI, 2007, São José dos Campos. Anais... São José dos Campos: ELAIC. 2007. p. 196-199. 